\title{
Augmented Reality as a Tool in the Teaching-Learning Process of Natural Sciences in a Primary Institution
}

\author{
Ximena A. Rosero Benavides, Israel D. Herrera-Granda ${ }^{*}$, Erick P. Herrera Granda \\ Postgraduate Institute, Universidad Técnica del Norte, Ibarra, 100102, Ecuador
}

Received April 27, 2020; Revised June 2, 2020; Accepted January 25, 2021

\section{Cite This Paper in the following Citation Styles}

(a): [1] Ximena A. Rosero Benavides, Israel D. Herrera-Granda, Erick P. Herrera Granda, "Augmented Reality as a Tool in the Teaching-Learning Process of Natural Sciences in a Primary Institution," Universal Journal of Educational Research, Vol. 9, No. 4, pp. 781 - 791, 2021. DOI: 10.13189/ujer.2021.090410.

(b): Ximena A. Rosero Benavides, Israel D. Herrera-Granda, Erick P. Herrera Granda (2021). Augmented Reality as a Tool in the Teaching-Learning Process of Natural Sciences in a Primary Institution. Universal Journal of Educational Research, 9(4), 781 - 791. DOI: 10.13189/ujer.2021.090410.

Copyright $\bigcirc 2021$ by authors, all rights reserved. Authors agree that this article remains permanently open access under the terms of the Creative Commons Attribution License 4.0 International License

\begin{abstract}
Recent challenges for strategic educational planning in Ecuador request implement Information and Communication Technologies (ICT) in different levels of educational institutions. However, there's a notable lack of successful implementations of ICTs on national educational institutions, which causes several problems in student's learning cycle such as loss of attention, motivation and innovation. These problems are further aggravated at the level of primary education institutions. Nevertheless, this paper demonstrates the feasibility of implementing digital tools with augmented reality (AR) for teaching and learning of Natural Sciences (NC) in the Cesar Mosquera Primary School located at the northern zone of Ecuador. To this end, we began by identifying digital strategies that facilitate the teaching of $\mathrm{NC}$ as an element of feedback and development of spatial imagination. Next, a diagnosis was made of the weaknesses of both teachers and students in the teaching of $\mathrm{NC}$ at primary school level. A mixed research method was applied, using quantitative techniques such as survey analysis and using qualitative techniques such as direct observations, to make a content analysis applied to teacher planning. Then, cutting-edge technologies such as augmented reality deployed on easily accessible devices such as Smartphones or Tablets were implemented using Curiscope-Virtuali-Tee software and web 3.0 virtual classroom tools that were applied during the COVID-19 pandemic. Once implemented, the proposed AR system was compared with classic teaching methods. Finally, the feasibility of applying AR in the mentioned institution was
\end{abstract}

demonstrated due to all students approved the final test of acquired knowledge in each class taken.

Keywords Primary Education, ICT, Augmented Reality, Natural Sciences, Teaching during COVID-19

\section{Introduction}

Within the academic context, several tools have emerged as an alternative to optimize the pedagogical processes in education; among these tools, we can highlight Virtual Reality (VR) and Augmented Reality (AR).

The VR emerged in the late 1960s. Through graphic devices, it transports the user to a different reality, mostly projected in three dimensions [1]. However, a major disadvantage lies in the user's disconnection from the real world, giving this technology a sense of surrealism, which could cause problems in the learning cycle.

AR emerged in the early 1990s, and from its very name, it encompasses the concept of improving or increasing reality. It could be said that this technology is an evolution of RV. However, AR allows the user to continue to be located in the real world by means of visual devices and to combine it with a virtual reality superimposed on it. [2]. This is why AR has also been called Mixed Reality, since the information superimposed on the real world can be dynamically visualized through a great diversity of devices, providing "increases" in the perception of data that the user 
is receiving while he is moving, which could theoretically improve the existing reality. These increments are interesting for the education field, since in that way it would be possible to optimize the time used in the learning cycle that is: learning more in a shorter time.

Over the years, education has been evolving and adapting to it, using the most up-to-date educational models. For this reason, it is necessary to promote the use of methodological strategies in the teaching of the Natural Sciences, whether on a temporary or a motivational basis. In order to promote the interest in these sciences, particularly, considering that students are not exposed to real challenges in the subject. It is also essential to mention the didactic part in which the use of emerging technological means such as augmented reality (AR) can be made in the teaching process of the Natural Sciences.

Consequently, the problem we face in this research work is that students perceive the subject of natural sciences as too complex and this could be the cause of their lack of interest in learning it.

It is important to understand that in primary education it is not a question of students studying sciences in relation to directed careers, but rather that they understand the importance of all sciences and that they develop the potential of each individual, thus acquiring a more generalized education. Specifically we seek to develop spatial imagination, for this purpose we propose to make use of virtualization as is the case of augmented reality, focused on the learning styles of human beings [3].

Currently, we are immersed in a digitalized culture, focused on various social, educational and administrative fields, among others. Innovation in education through technology is a great didactic and pedagogical challenge, in which the educator can teach from any place, regardless of time or space, with the use of digitized resources, multimedia, such as web 2.0 and 3.0, where the student constantly navigates and develops skills and motivation to learn.

In Ecuador, the approach of the Digital Education Agenda 2017 - 2021 includes great challenges to improve the quality of education through the incorporation of Information and Communication Technologies (ICT), taking the traditional school towards the knowledge society, which is, transforming it into a digital school [4]. Therefore, the main objective of this paper is to implement an AR system as a didactic tool in the process of teaching and learning Natural Sciences within the seventh year of basic education of the Cesar Antonio Mosquera Educational Unit. To do so, as specific objectives, it will be necessary to diagnose the use of techno-pedagogical strategies used by teachers in the process of teaching and learning Natural Sciences in the seventh year of basic education. In addition, it will be necessary to design an AR system that will make the process of teaching and learning in the Natural Sciences more dynamic and stronger. Next, it will be necessary to evaluate the proposal of AR through a pilot experiment that will allow to evidence the academic performance of students and to analyze the data obtained.

The scientific contribution of this work lies in its application to primary education students, and especially at a crucial time, since during the execution of this study the classes had to be interrupted by the imminent risk caused by the COVID-19 pandemic. For that reason we had to take contingency actions, i.e. use of web 3.0 tools combined with AR to minimize the interruption of the cycle of knowledge, the cycle of preparation was short because there was no a prior warning, so the responses had to be immediate and the resources were scarce. However, this study contributes with the development of a model for the implementation of the proposed methodology, which is described in detail so that, this initiative could be replicated in other primary education institutions.

Thus, this work is structured as follows: section one explains the concepts used and the problems faced by primary education institutions in Ecuador, then reviews the state of the art on worldwide implementations of AR in the educational field with the aim of inspiring the development of the model proposed in this work. Section two describes in detail the process to be followed to implement an anatomy teaching system at the primary school level with the support of AR and web 3.0 tools and atlow cost. Section three analyzes quantitatively and qualitatively the results obtained after implementing the proposed system against classical blackboard teaching methods. Finally, the results obtained are discussed.

\section{Review of the state of the art}

Numerous applications of AR have been developed in the educational context, proposing the implementation of a two-phase model: preparation and experimentation, to optimize the teaching process in primary school disabled children, in which identification tags, a webcam and an image-processing device are used, thus providing an alternative learning method that allows disabled children to access knowledge effectively. However, the correct implementation required the first phase of preparing teachers to adopt this new technology [5].

In the same way, [6] in their work show how AR implemented in chemistry teaching improves the grades obtained by high school students compared to traditional teaching methods. Lather, [7] analyzed the benefits of teaching the functioning of the human heart with the help of RA, the results are shown in a quantitative way.

On the other hand, Klimova et al. [8], presents a review of existing teaching practices supported by the AR, includes a classification of acquired skills according to learning outcomes, and finally shows the types of assessment that can be applied under the VR approach and by institution. In the same way, Chen et al. [9], present a paper reviewing the process of teaching experimental sciences at universities with the support of the AR. 
In the year 2019 the work of Gybas et al [10]., which shows an application of $\mathrm{AR}$ in the teaching process to students with mental disabilities, this work concludes by demonstrating that all students studied were able to use the learning platform through mobile devices.

Later, Schaffernak et al.[11], present an exploratory study on the potentialities of the use of $\mathrm{AR}$ in the educational context of airplane pilots and considering gender equity, especially in technical sciences.

Time later, Gindy et al.[12], combine some AR software to form a platform with which they simulate the water cycle, in an institution of primary education, so that they seek to develop in children better decisions that allow them to make critical decisions in the future. In the meantime, Chytas et al.[13], present a comprehensive review of the role of AR in anatomy teaching, with the aim of motivating students to study anatomy as well as promoting the use of AR in teaching.

\section{Case of study}

This research will be carried out at the Cesar Antonio Mosquera Primary Unit, located in the Province of Carchi, Canton Tulcan, Ecuador, which has 19 teachers and 250 students. Given that this study will be carried out within a fiscal institution, an authorization has been obtained for the collection of the data so that the integration of the proposed objectives can be achieved without infringing upon any individual right. These studies were done involving a community of children, adolescents and adults.

\section{Methodology}

A three-phased approach (PEEv) was applied to this investigation: Preparation (P), Experimentation (E) y Evaluation (Ev), Although this research uses qualitative elements such as direct observations during the teaching and assessment cycle, and in turn uses surveys and evaluations which represent the use of a quantitative approach, one could say that we have a mixed research approach. However, the quantitative approach will be predominant, as evaluations will be conducted through data collection on numerical scales. As shown in figure 1.

\section{Preparation $-\mathbf{P}$}

It considers techniques such as the survey, aimed at teachers and students that will identify the use of digital strategies applied by their teachers and the effectiveness in students as a means of incentive in the subject of Natural Sciences.

It is relevant to detail also, the direct observation in taking recorded attitudinal and analysis of the use of augmented reality, with a sequential order in correspondence to the research in compliance with the objectives.
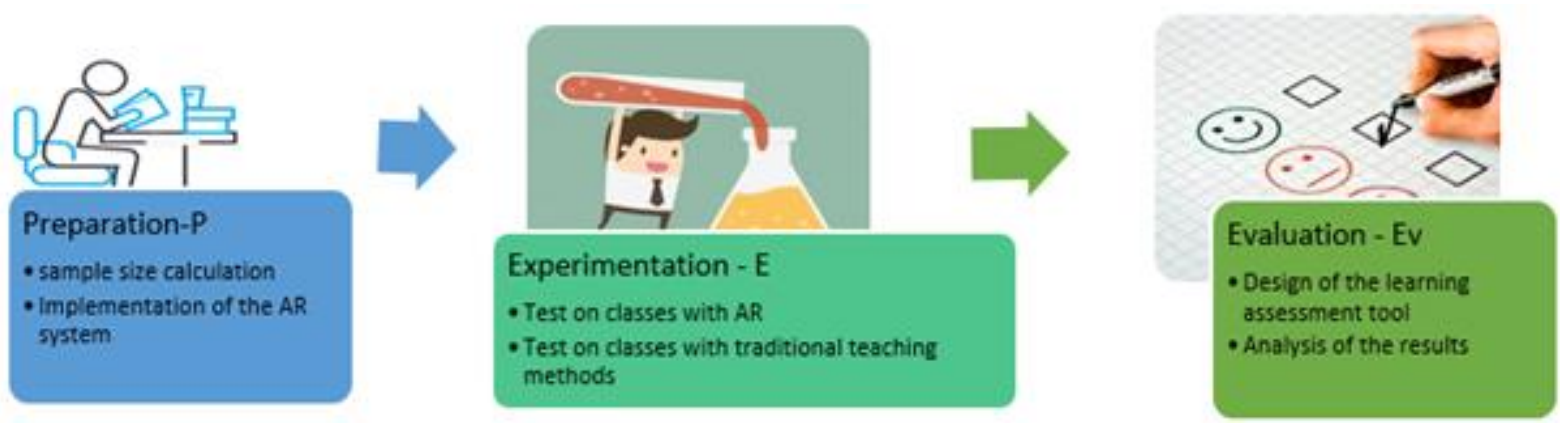

Figure 1. Methodology applied to implement AR in Natural Science classes 


\section{Calculation of representative sample size}

The stratified probability sampling technique was used. Specifically, for our case study it is convenient to use the formula for the calculation of the representative sample size $(n)$, wherethe total size of the finite population is known $(N)$ [14], which comprises the 250 students of the primary education unit studied.

Where:

$$
n=\frac{Z^{2} * P * Q * N}{E^{2}(N-1)+Z^{2} * P * Q}
$$

$Z$ : Confidence level or reliability margin, in this case, for a 95\% confidence level then $Z=1,96$.

$P$ : proportion of students from the A and B parallels Where students from parallel A will be taught with AR and students from parallel B will not be taught with AR,

$Q=1-P:$ Proportion of students from parallels A and $\mathrm{B}$, in this case the two parallels will have equal proportions, i.e. $50 \%$.

$N$ : Total number of students in stratum 1 and 2.

$E$ : Estimation error or maximum difference between the sample ratio and the proportional ratio that the research team is willing to accept depending on the confidence level defined for the study. In this case $E=10 \%$. $n=70$ students from parallels A and B to be surveyed at the educational institution. In conclusion, for a population of 250 students from parallels A and B, with a confidence level of $95 \%$ and an estimation error of $10 \%$, it is necessary to survey a total of 70 students from parallels $\mathrm{A}$ and $\mathrm{B}$, where 35 students will be surveyed in course A and 35 students will be surveyed in course B. In order to know the effectiveness of the teaching method supported with AR.

\section{Implementation of the AR system}

Prior to the implementation of the AR teaching system, it is important to conduct tests to determine if the teachers used in the trainings are able to use the device and the AR T-shirt provided by Curiscope-Virtuali-Tee [15]. At this point, the technique of direct observation was applied, since initially the equipment was given to the teachers to determine if they were capable of using the devices without previous training. Without altering their conditions, their reactions were recorded photographically for one hour. With this, it was possible to determine that they needed to be trained previously to use the devices. This preparation cycle was illustrated in figure 2 .

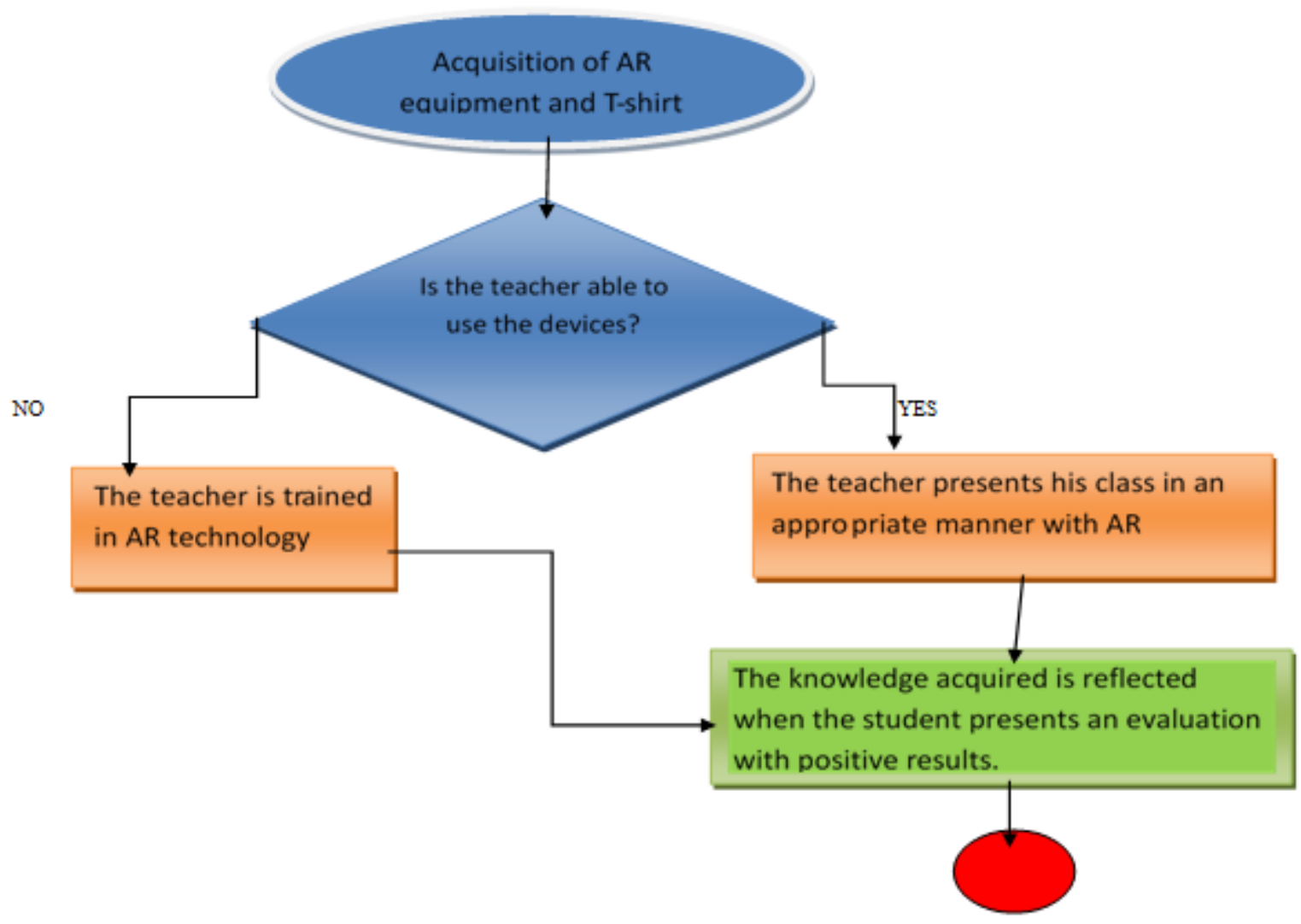

Figure 2. Prior preparation of teachers and RA devices 


\section{Experimentation - E}

At this stage, AR technology was implemented through the application available for both PC and Android Curiscope-Virtuali-Tee [15] in addition, a AR T-shirt that serves as a background to observe through devices such as PCs, cellphones or tablets the anatomy information stored in the AR system and display this data in real time adapting to the movements of the teacher.

Through this application, users will be able to visualize the respiratory system in its natural state. The respiratory system contains the airways, lungs and respiratory muscles that cause the movement of air inside and outside of the human body. The organs that are part of the respiratory system are: nose, pharynx, larynx, trachea, bronchi, lungs and diaphragm, all these aspects are shown interactively in a Smartphone through the application.

The above-mentioned AR T-shirt contains a vectorized design that activates the augmented reality application when pointing with the device either mobile phone or tablet, in which the application is installed. In this case, a template with anatomy data was used, which is certified by anatomy specialists.

The AR T-shirt, by means of a code printed on its front, provides information to the real image when it is displayed through a Smartphone or tablet. The application is designed to make the experience as real as possible, since even when you get close to the body you can see the body's organs from different viewing angles. As shown in figure 3.

\section{Technical concepts used}

The topics to be instructed will belong to the subject of natural sciences, specifically three classes will be taught:

- The human circulatory system.

- The human digestive system.

- The human respiratory system.

The circulatory system is responsible for distributing oxygen and food throughout the body, and collects carbon dioxide and excretion products from the cells. It is made up of: a circulating fluid called blood, a pump that drives the blood called the heart.

The main function of the circulatory system is to transmit nutrients such as amino acids, electrolytes, and lymph, as well as gases, hormones, and blood cells, among others, to the cells of the body. This system is also responsible for collecting metabolic wastes that are eliminated later by the kidneys, in the urine. These concepts are much more interpretable through schematization.

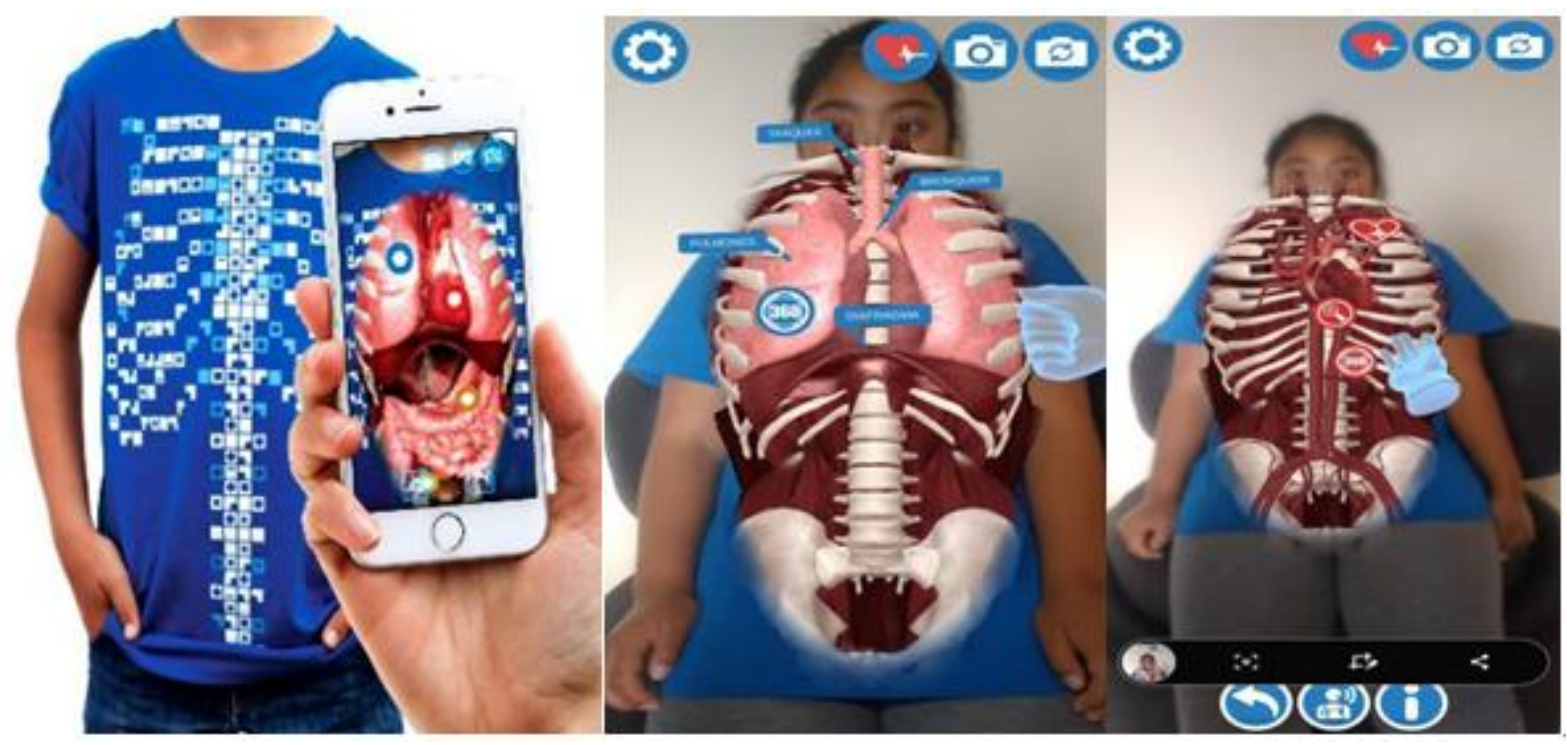

Figure 3. Experimenting with RA 
In addition, these concepts can be transmitted to the students through virtual classes using the interactive zoom class platform. Integrating perception and interaction with the real world with the 7th "A" students Note how in this case AR technologies are efficiently combined with web 3.0 tools as shown in Figure 4.

The digestive system is the set of organs: mouth, pharynx, esophagus, stomach, small intestine and large intestine, which are in charge of the digestion process. Digestion is the process of transforming food so that it can be absorbed and used by the cells of the body.

In the same way as in the previous case, AR was combined with web 3.0 tools in virtual classes to the seventh "A" students. As shown in figure 5.

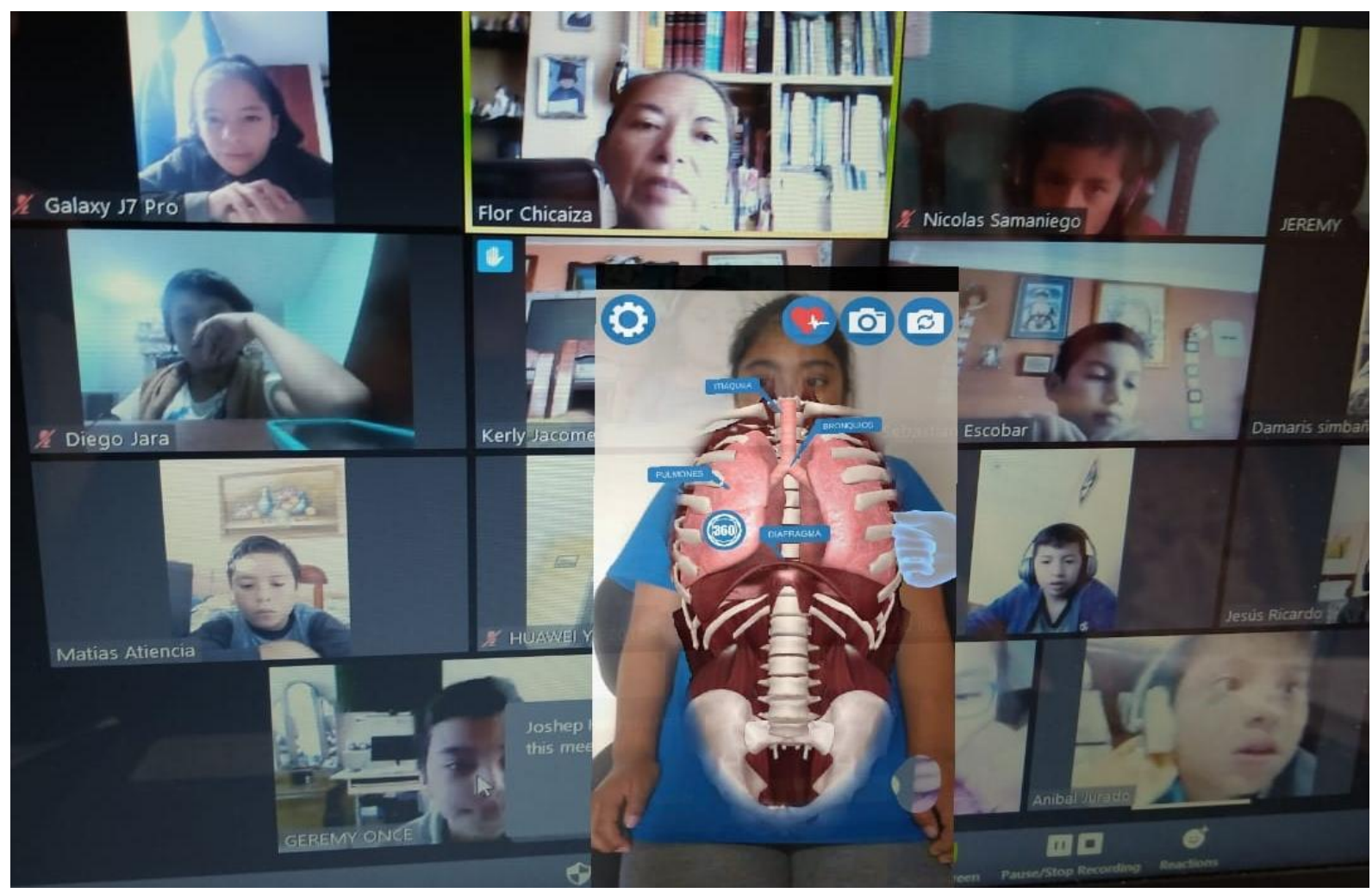

Figure 4. Class about the circulatory system.

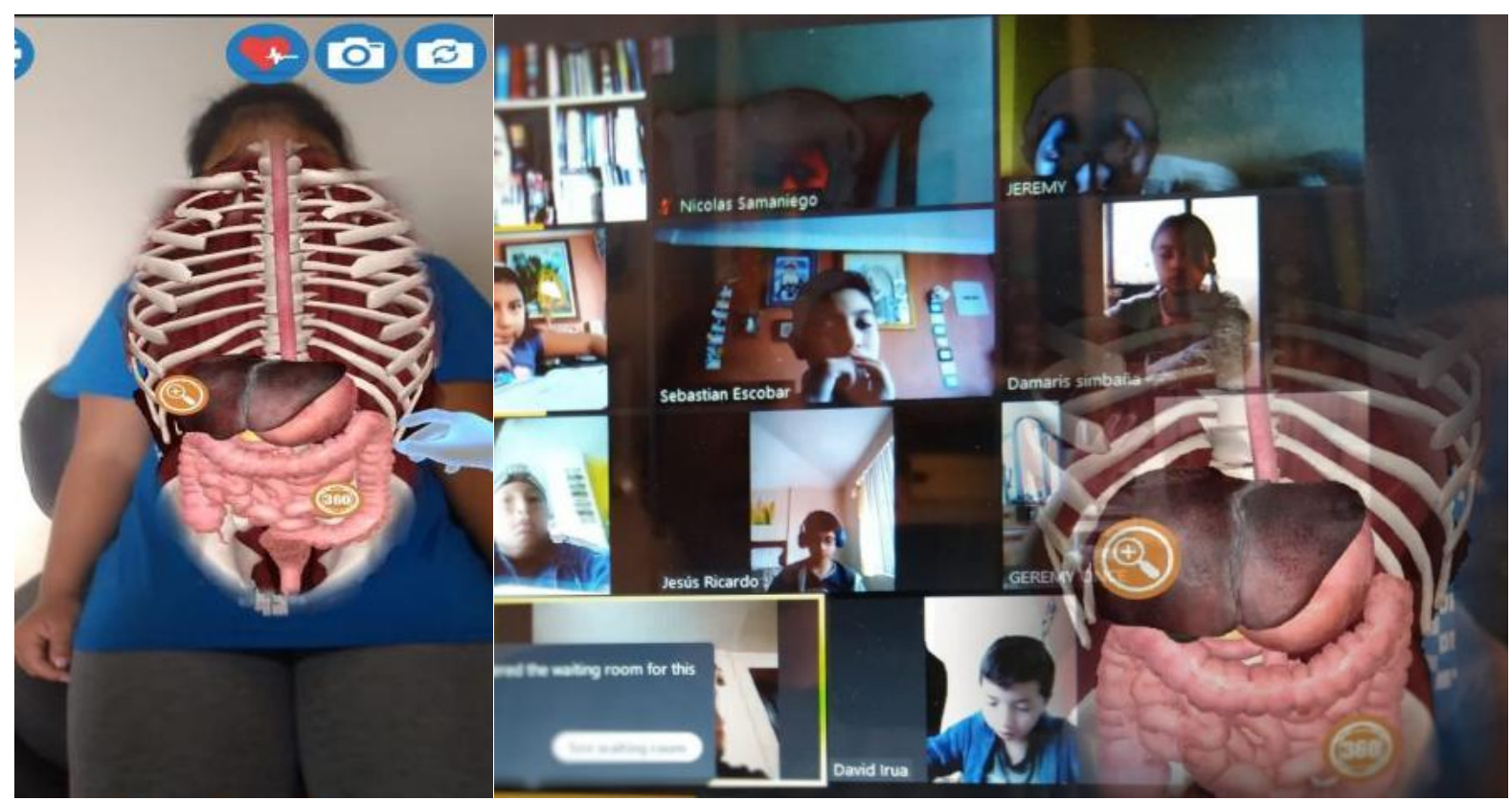

Figure 5. Class about the digestive system 


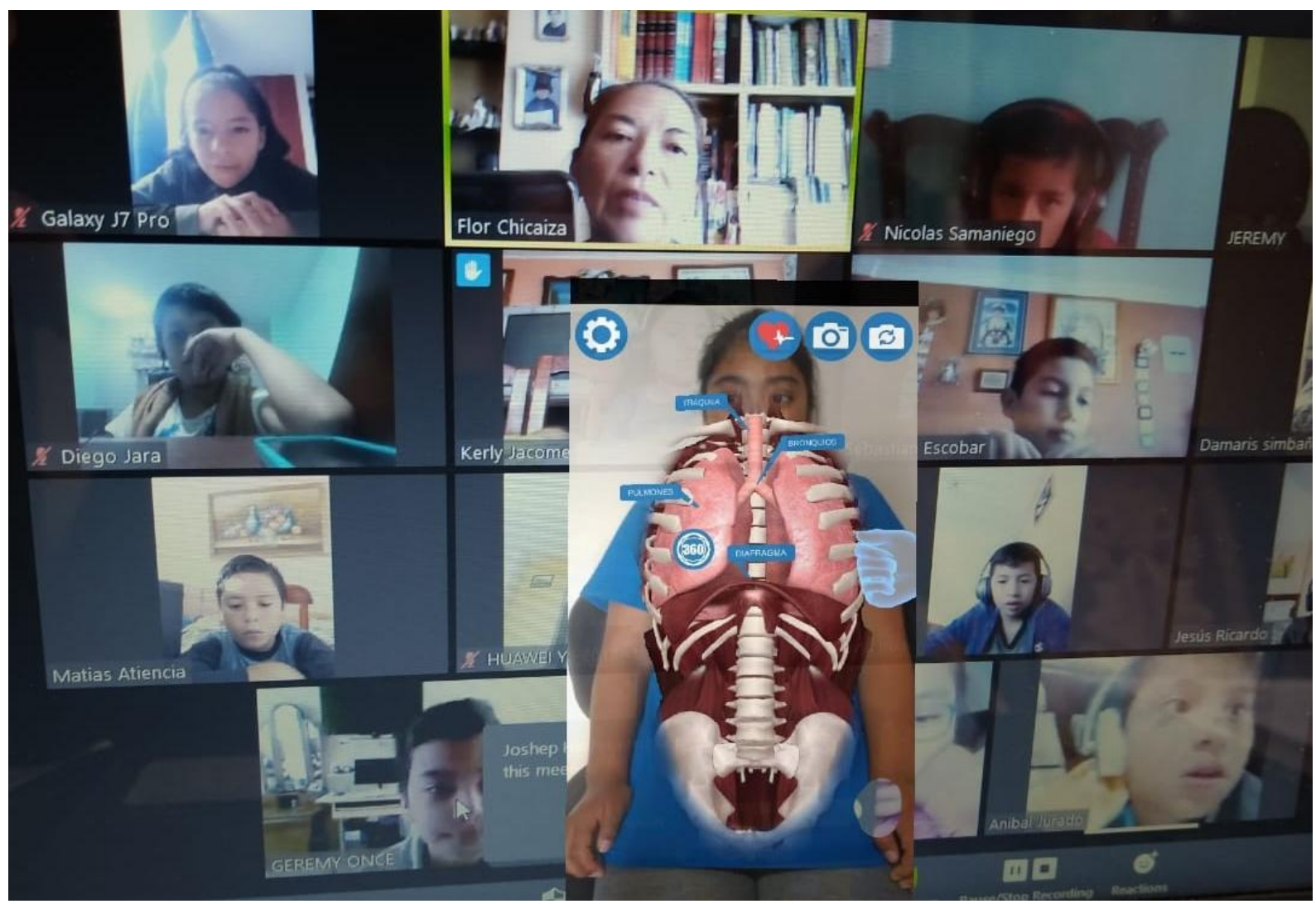

Figure 6. Class about the respiratory system

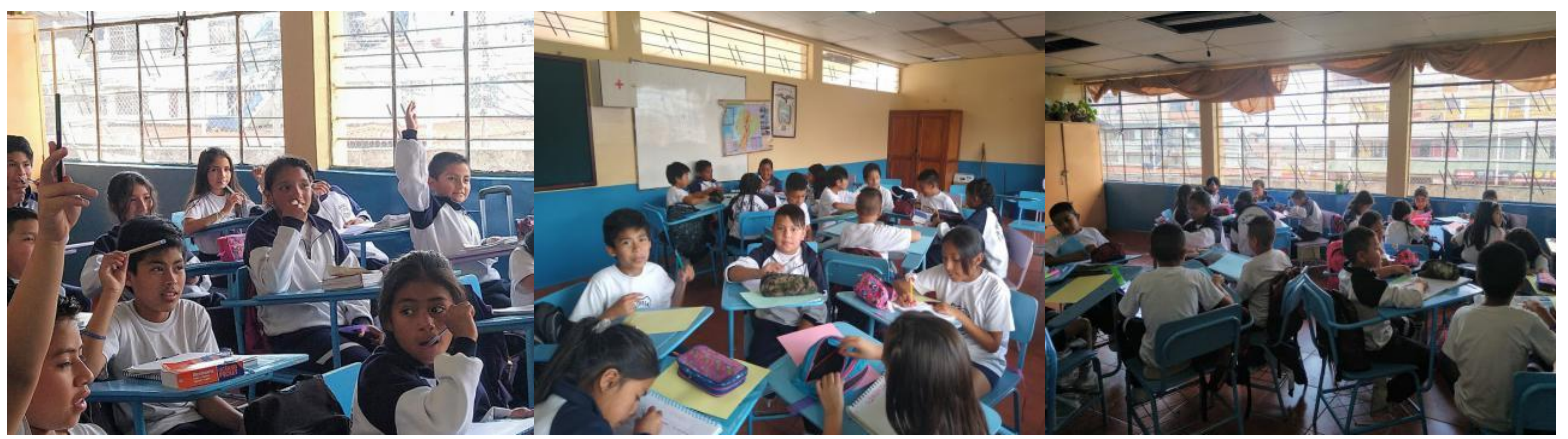

Figure 7. Reinforcement stages to a face-to-face class of AR supported anatomy

Similarly, the respiratory system class was taught to students of the seventh A virtually through the zoom platform, using AR, which involves the incorporation of data and digital information in real time and web 3.0 tools, as shown in Figure 6.

In addition, experiments were carried out in $\mathrm{AR}$ supported teaching through face-to-face classes, which provide opportunities for collaboration among students. Within this theme, activities were organized so that children could work in groups after receiving the class with augmented reality. Subsequently, opinion groups were set up on the subject. As shown in Figure 7.

\section{Evaluation - Ev}

In order to test the efficiency of the teaching of natural sciences at primary level, a study was carried out on a sample of 70 students in the seventh year of the Cesar Antonio Mosquera Educational Unit, on whom their knowledge acquired will be evaluated through a survey that aims to assess compliance with learning outcomes.

That is, information was collected from students corresponding to the sample size calculated using a survey and assessment instrument shown in Table 1. This instrument was applied to these students immediately after each class

\section{Design of the learning assessment instrument for primary school students}

The heading shown in Table 1 has been designed to evaluate the learning outcomes acquired by primary school students. It will be applied to two courses of students with similar characteristics, both in level and quantity, and 
belonging to the same educational institution. Course A with 35 students will be instructed with the support of the AR platform designed for this study, while course B with 35 students will be instructed under the classical methods. The mentioned assessment instrument consists of five questions, among which, questions 1 and 2 the way students perceive the learning process in each class taught contain discrete quantitative variables with a scale from 1 to 10. While, questions 3,4 and 5 contain ordinal qualitative variables, whose scale can be treated as a quantitative variable from 1 to 10 using the following values \{Totally disagree 1 , Somewhat disagree 3 , Partially disagree 4 , Neither agree nor disagree 6, Partially agree 7, Somewhat agree 9 , and Totally agree 10$\}$. This process of assigning quantitative values to qualitative variables can be called data mining [16], [17], [18].

Table 1. Instrument for Assessing Learning Outcomes

\begin{tabular}{|c|c|c|c|c|c|c|}
\hline \multicolumn{7}{|c|}{$\begin{array}{l}\text { Mark with an } \mathrm{X} \text { from } 1 \text { to } 10 \text { the difficulty level of the contents of this class. Where } 1 \text { means that the class was very easy and } 10 \text { means that } \\
\text { it was very complex. }\end{array}$} \\
\hline 1 & 2 & 4 & 5 & 7 & 8 & 10 \\
\hline \multicolumn{7}{|c|}{$\begin{array}{l}\text { Mark with an X from } 1 \text { to } 10 \text {, how much you like the subject of natural science. Where } 1 \text { means you don't like the subject and } 10 \text { means it is } \\
\text { one of your favorite subjects. }\end{array}$} \\
\hline 1 & $2 \quad 3$ & 4 & $5 \quad 6$ & 7 & 8 & 10 \\
\hline \multicolumn{7}{|c|}{ Do you think that the use of technology is important to better understand the contents of the subject of natural sciences } \\
\hline $\begin{array}{l}\text { Strongly } \\
\text { disagree }\end{array}$ & $\begin{array}{l}\text { Somewhat } \\
\text { disagree }\end{array}$ & $\begin{array}{c}\text { Partially } \\
\text { disagreeing }\end{array}$ & $\begin{array}{l}\text { Neither agree nor } \\
\text { disagree }\end{array}$ & Partially agreed & $\begin{array}{l}\text { Somewhat in } \\
\text { agreement }\end{array}$ & I totally agree. \\
\hline \multicolumn{7}{|c|}{$\begin{array}{l}\text { Do you think it is important that natural science teachers should use technology such as tablets, devices, or augmented reality to enhance } \\
\text { their students' learning? }\end{array}$} \\
\hline $\begin{array}{l}\text { Strongly } \\
\text { disagree }\end{array}$ & $\begin{array}{l}\text { Somewhat } \\
\text { disagree }\end{array}$ & $\begin{array}{c}\text { Partially } \\
\text { disagreeing }\end{array}$ & $\begin{array}{l}\text { Neither agree nor } \\
\text { disagree }\end{array}$ & Partially agreed & $\begin{array}{l}\text { Somewhat in } \\
\text { agreement }\end{array}$ & I totally agree. \\
\hline \multicolumn{7}{|c|}{ Do you think that the use of the augmented reality t-shirt allowed you to better understand the contents taught during this class? } \\
\hline $\begin{array}{l}\text { Strongly } \\
\text { disagree }\end{array}$ & $\begin{array}{c}\text { Somewhat } \\
\text { disagree }\end{array}$ & $\begin{array}{c}\text { Partially } \\
\text { disagreeing }\end{array}$ & $\begin{array}{l}\text { Neither agree nor } \\
\text { disagree }\end{array}$ & Partially agreed & $\begin{array}{l}\text { Somewhat in } \\
\text { agreement }\end{array}$ & I totally agree. \\
\hline
\end{tabular}

\section{Test on circulatory system}

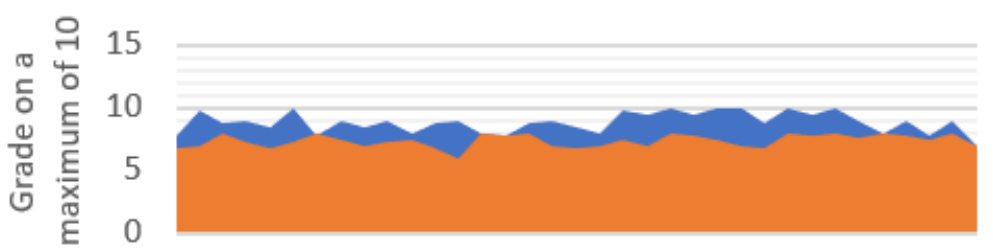

$1 \quad 3 \quad 5 \quad 7 \quad 9 \quad 11131517192123252729313335$

student

Test on digestive system

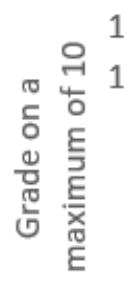

들

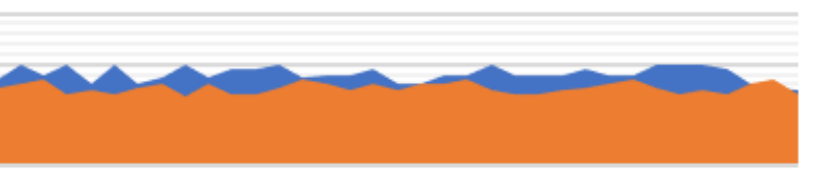

$1 \quad 3 \quad 5 \quad 7 \quad 911131517192123252729313335$

student

Test on respiratory system

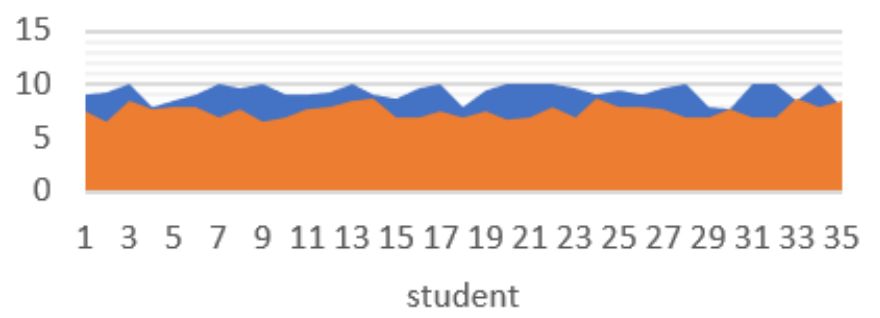

Paralell A with AR

- Paralell B with clasic methods
Paralell A with AR

- Paralell B with clasic methods
Paralell A with AR

Paralell B with clasic methods

Figure 8. Scores obtained by the students in the test 
Table 2. Final sample weighted scores survey outcome

\begin{tabular}{|c|c|c|}
\hline \multicolumn{3}{|c|}{ Class of Circulatory System } \\
\hline Paralell: & $\begin{array}{c}\text { Paralell A with } \\
\text { AR }\end{array}$ & $\begin{array}{l}\text { Paralell B with } \\
\text { classic methods }\end{array}$ \\
\hline Minimun & 7,00 & 6,00 \\
\hline 1st. quartile & 8,25 & 7,00 \\
\hline Median & 9,00 & 7,50 \\
\hline Mean & 8,87 & 7,39 \\
\hline 3st.quartile & 9,50 & 7,87 \\
\hline Maximun & 10,00 & 8,00 \\
\hline \multicolumn{3}{|c|}{ Class of Digestive system } \\
\hline Paralell: & $\begin{array}{c}\text { Paralell A with } \\
\text { AR }\end{array}$ & $\begin{array}{l}\text { Paralell B with } \\
\text { classic methods }\end{array}$ \\
\hline Minimun & 7,50 & 6,75 \\
\hline 1st. quartile & 8,75 & 7,00 \\
\hline Median & 9,00 & 7,75 \\
\hline Mean & 9,07 & 7,65 \\
\hline 3st.quartile & 9,75 & 8,00 \\
\hline Maximun & 10,00 & 8,50 \\
\hline \multicolumn{3}{|c|}{ Class of Respiratory Sistem } \\
\hline Paralell: & $\begin{array}{c}\text { Paralell A with } \\
\text { AR }\end{array}$ & $\begin{array}{l}\text { Paralell B with } \\
\text { classic methods }\end{array}$ \\
\hline Minimun & 7,75 & 6,50 \\
\hline 1st. quartile & 9,00 & 7,00 \\
\hline Median & 9,50 & 7,75 \\
\hline Mean & 9,28 & 7,59 \\
\hline 3st.quartile & 10,00 & 8,00 \\
\hline Maximun & 10,00 & 8,75 \\
\hline
\end{tabular}

\section{Results}

Initially we proceeded to evaluate quantitatively the knowledge acquired by the students through a test of knowledge on a maximum of 10 points (Test), for each of the three classes taken; the results show a higher performance of the parallel A that took the class with AR devices, as shown in Figure 8.

However, the previous figures, although they allow us to appreciate the advantage of the grades obtained by the students of parallel A. They are not very correct since they traditionally compare students from two different parallels that are not correlated, so it is interesting to analyze the descriptive statistics obtained using the software Rstudio for each parallel in the three classes, as shown in table 2.

After this first analysis of descriptive statistics on the scores obtained by students in the three classes (test), it is possible to note that the median is a good measure of central tendency for the three classes where the tests were taken. Thus, a notable advantage can be noted in the grades of all the students of parallel A in the three classes taken. Note also that in none of the three cases did the students of parallel A obtain a grade lower than 7. That is, no student of course A would fail in a class with AR according to our current grading system, which gives us a good picture regarding the benefits that can be obtained by applying AR in the primary education classroom. As can be seen in Figure 9.

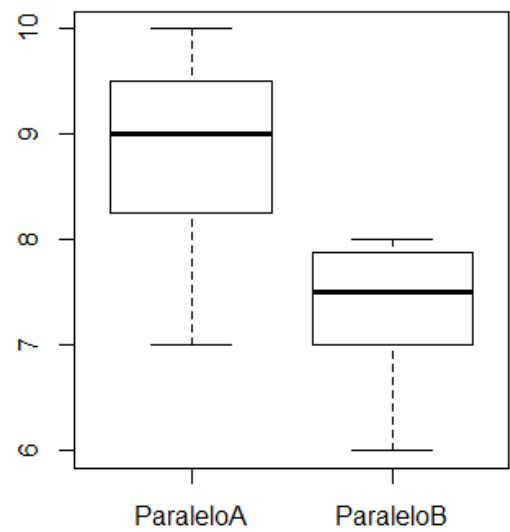

Circulatory System

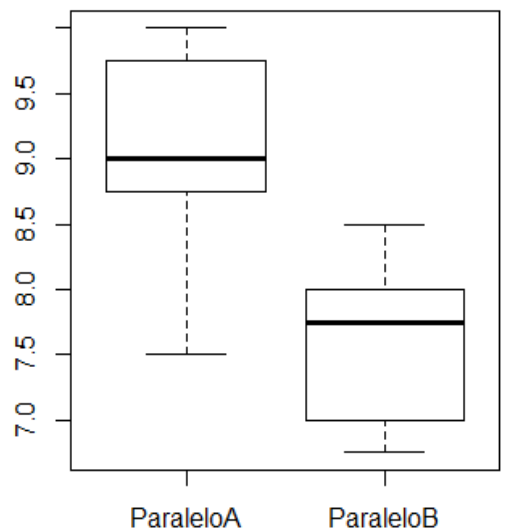

Digestive system

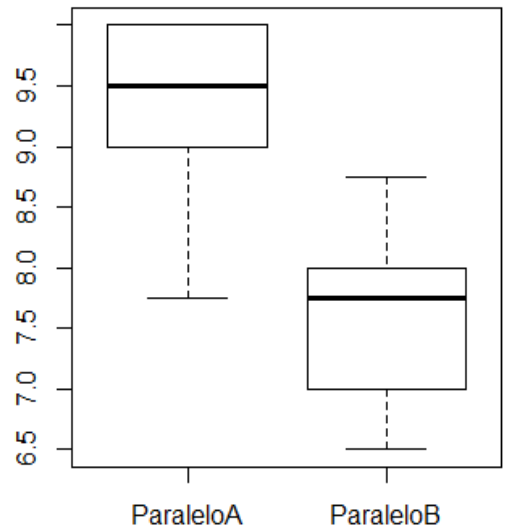

Respiratory Sistem

Figure 9. Box plot diagram of the scores obtained by the students in the test 
Once the data mining process has been carried out in which the 5 questions of the assessment instrument are converted to a quantitative scale from 1 to 10 , as well as the grade of the evaluation of the students' learning. With this purpose, it was possible to consolidate a quantitative database, which can be processed with the help of the software Rstudio. The tests carried out include mustache and box diagrams between all the questions, in this type of analysis it is also important to group each of the variables corresponding to the five questions and the quantitative evaluation and box diagrams differentiated by the parallel.

For the class of the circulatory system, it can be noted by the median that the classes supported with AR in the parallel A obtain a better performance in all the questions with respect to the parallel without RA. In addition, it is important to note that the students indicate that with AR the difficulty to learn is smaller through question 1 . As shown in Figure 10.

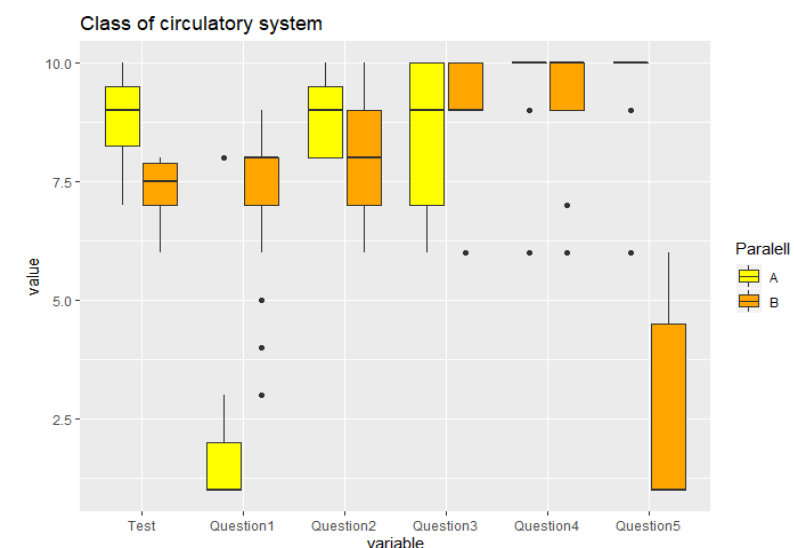

Figure 10. Evaluation of the classes of the circulatory system, parallel A used AR

For the class of the digestive system it can be noted through the median that the classes supported with AR in the parallel A obtain a better performance in all the questions with respect to the parallel without RA. In addition, it is important to note that the students indicate that with AR the difficulty to learn is smaller through question 1. As shown in Figure 11.

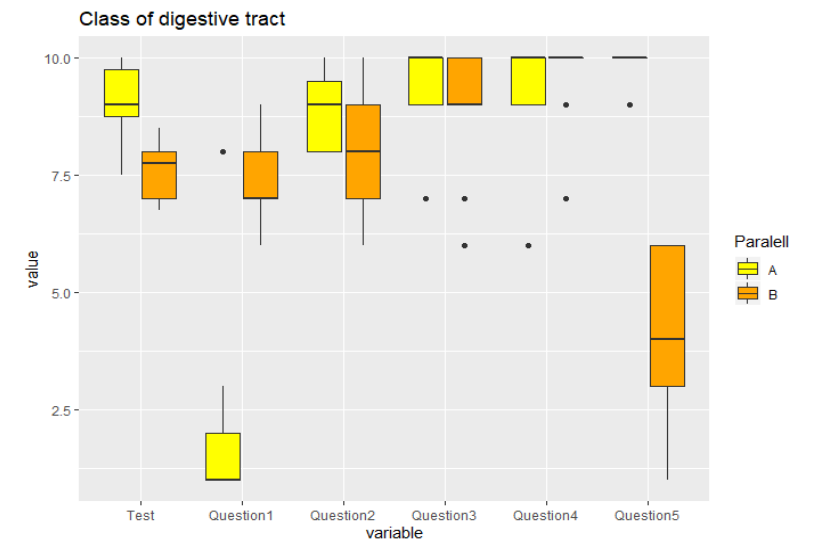

Figure 11. Evaluation of the classes of the digestive system, parallel A used AR
For the respiratory or breathing system class it can be noted by the median that the classes supported with AR in the parallel A obtain a better performance in all questions with respect to the parallel without RA. In addition, it is important to note that most students indicate that with AR the difficulty to learn is less through question 1 . As shown in Figure 12.

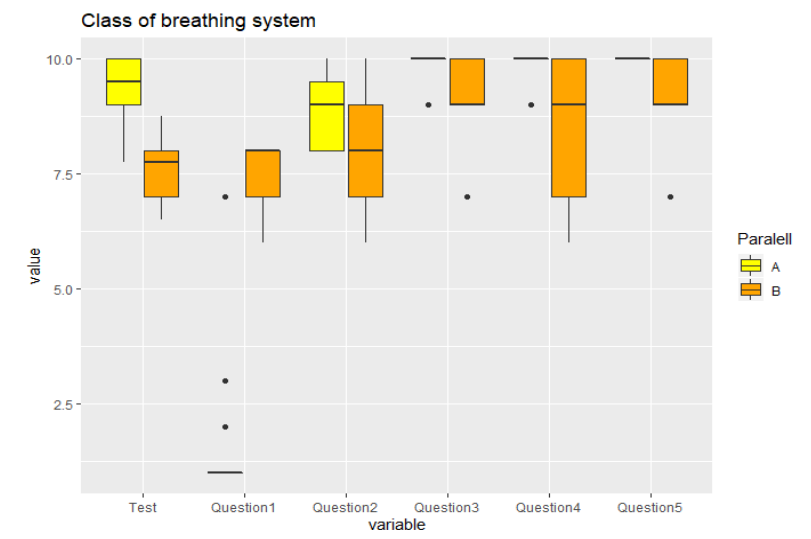

Figure 12. Evaluation of respiratory system classes, parallel A used RA

\section{Conclusions}

Firstly, the methodologies proposed by this study have been statistically validated, which combine web 3.0 tools by means of online participatory classes with AR in a primary education institution, which due to the COVID pandemic situation we are going through were totally feasible to implement and at a low cost. Thus, the main objective of this research is fulfilled

Secondly, descriptive statistics analyses show that the proposal of teaching with RA not only surpasses to the classic teaching method in which the teacher imparts his or her knowledge of natural sciences on the blackboard. However, it was also possible to demonstrate the great acceptance and predisposition that students had towards this type of technology, which was combined in a timely manner, and it made possible to continue with the learning cycle even in situations of global concern such as the COVID-19 pandemic. In addition, it was possible to notice the rapid adaptation to the use of web3.0 tools such as interactive online classes with primary school students. With this, the second one is fulfilled, which consists in diagnose the use of techno-pedagogical strategies used by teachers in the process of teaching and learning Natural Sciences in the seventh year of basic education. And the final objective that consist in evaluate the proposal of AR through a pilot experiment that will allow to evidence the academic performance of students and to analyze the data obtained

It is worth mentioning that the development of this research project allowed us to demonstrate the scarce application of ICTs in Ecuador's primary education institutions, making this one of the few works of this type 
in the area. However, this work focused on developing a standardized process for the implementation of $A R$ in primary education, which consists of three phases - PEEv, which will allow us to replicate this work in other primary education institutions, thus fulfilling the objectives initially set. The mentioned standardized process consists in the implementation of RA, which dynamizes and strengthens the teaching of Natural Sciences in basic education; therefore, the second specific objective has been completed.

To summarize the above, this paper demonstrates the feasibility of implementing an AR System in primary education which, when combined with virtual collaborative classes with web 3.0 technologies, represent a contingency tool to avoid the suspension of classes and the consequent interruption of the learning cycle in high-risk situations for the population such as pandemics.

\section{REFERENCES}

[1] Blanchard, C., Burgess, S., Harvill, Y., Lanier, J., Lasko, A., Oberman, M., Teitel, M.: Reality Built For Two. A virtual reality tool. Proc. - 1990 Symp. Interact. 3D Graph. 24, 35-36 (1990). doi:10.1145/91394.91409

[2] Rath, D., Satpathy, I., Patnaik, B.C.M.: Augmented reality (Ar) \& virtual reality (Vr)-a channel for digital transformation in industrialization fostering innovation \& entrepreneurship. Int. J. Innov. Technol. Explor. Eng. 8, 3228-3236 (2019). doi:10.35940/ijitee.J1167.0881019

[3] Morales, L.M., Mazzitelli, C.A., del Carmen Olivera, A.: La enseñanza y el aprendizaje de la Física y de la Química en el nivel secundario desde la opinión de estudiantes. Rev. electrónica Investig. en Educ. en ciencias. 10, 11-19 (2015)

[4] Ministerio de educación: Agenda Educativa Digital 2017-2021,

https://educacion.gob.ec/agenda-educativa-digital/

[5] Lin, C.Y., Hung, P.H., Lin, J.Y., Lun, H.C.: Study on augmented reality as a teaching aid for handicapped children, https://www.scopus.com/inward/record.uri?eid=2-s2.0-779 $55456080 \&$ doi $=10.4028 \% 2 \mathrm{Fwww}$.scientific.net\%2FKEM. 439-440.1253\&partnerID=40\&md5=1da3a47a646a3651b2 4859b5d168079f, (2010)

[6] Abbasi, F., Waseem, A., Ashraf, E.: Augmented reality based teaching in classrooms. In: 2017 International Conference on Communication, Computing and Digital Systems, C-CODE 2017. pp. 259-264. Institute of Electrical and Electronics Engineers Inc., Department of Computer Science, Bahria University, Islamabad, Pakistan (2017)

[7] Nuanmeesri, S.: The augmented reality for teaching Thai students about the human heart. Int. J. Emerg. Technol. Learn. 13, 203-213 (2018). doi:10.3991/ijet.v13i06.8506

[8] Klimova, A., Bilyatdinova, A., Karsakov, A.: Existing
Teaching Practices in Augmented Reality. In: V., H., A., B., A., K., and A., B. (eds.) 7th International Young Scientists Conference on Computational Science, YSC 2018. pp. 5-15. Elsevier B.V., ITMO University, Kronverksky, 49, St Petersburg, Russian Federation (2018)

[9] Chen, C., Yu, T., Wang, J.: The Exploration of Augmented Reality Technology Applied in Colleges' Experimental Teaching. In: 9th International Conference on Information Technology in Medicine and Education, ITME 2018. pp. 652-655. Institute of Electrical and Electronics Engineers Inc., Educational Technology Center, Naval Medical University of Chinese PLA, Shanghai, China (2018)

[10] Gybas, V., Klubal, L., Kostolányová, K.: Using augmented reality for teaching students with mental disabilities. In: T.E., S., T.E., S., T.E., S., T.E., S., C., T., and T.E., S. (eds.) International Conference on Numerical Analysis and Applied Mathematics 2018, ICNAAM 2018. American Institute of Physics Inc., Faculty of Education, Department of Information and Communication Technologies, Fráni Šrámka 3, Ostrava - Mariánske Hory, 709 00, Czech Republic (2019)

[11] Schaffernak, H., Moesl, B., Vorraber, W., Koglbauer, I.V.: Potential Augmented Reality Application Areas for Pilot Education: An Exploratory Study. Educ. Sci. 10, 86 (2020). doi:10.3390/educsci10040086

[12] Al-Gindy, A., Felix, C., Ahmed, A., Matoug, A., Alkhidir, M.: Virtual reality: Development of an integrated learning environment for education. Int. J. Inf. Educ. Technol. 10, 171-175 (2020). doi:10.18178/ijiet.2020.10.3.1358

[13] Chytas, D., Johnson, E.O., Piagkou, M., Mazarakis, A., Babis, G.C., Chronopoulos, E., Nikolaou, V.S., Lazaridis, N., Natsis, K.: The role of augmented reality in Anatomical education: An overview. Ann. Anat. 229, (2020). doi:10.1016/j.aanat.2020.151463

[14] Bernal, C.: Metodología de la investigación. Pearson Educación, México (2016)

[15] Curiscope corp: Curiscope Virtuali-Tee - Learn about the Human Body with AR, https://www.curiscope.com/product s/virtuali-tee

[16] Jácome Ortega, A.E., Caraguay Procel, J.A., Herrera-Granda, E.P., Herrera Granda, I.D.: Confirmatory Factorial Analysis Applied on Teacher Evaluation Processes in Higher Education Institutions of Ecuador, https://www.scopus.com /inward/record.uri?eid=2-s2.0-85078412027\&doi=10.1007 \%2F978-3-030-37221-7_14\&partnerID=40\&md5=4972954 ddbe34252baa3218d493dafa0, (2020)

[17] Jácome-Ortega, A.E., Herrera-Granda, E.P., Herrera-Granda, I.D., Caraguay-Procel, J.A., Basantes-Andrade, A. V, Ortega-Bustamante, M.C.: Algorithm customization to audit database in higher education institutions . RISTI - Rev. Iber. Sist. e Tecnol. Inf. 2019, 399-412 (2019)

[18] Imbaquingo, D.E., Herrera-Granda, E.P., Herrera-Granda, I.D., Arciniega, S.R., Guamán, V.L., Ortega-Bustamante, M.C.: Evaluation of university informatic security systems: Teacher evaluation system a case study . RISTI - Rev. Iber. Sist. e Tecnol. Inf. 2019, 349-362 (2019) 